Research Article

\title{
Multispectral Remote Sensing Utilization for Monitoring Chlorophyll-a Levels in Inland Water Bodies in Jordan
}

\author{
Nidal M. Hussein $\mathbb{1 D}^{1}$ and Mohammed N. Assaf $\mathbb{D}^{2}$ \\ ${ }^{1}$ Department of Civil Engineering, University of Petra, Amman, Jordan \\ ${ }^{2}$ School of Natural Resources Engineering and Management, German Jordanian University, Amman, Jordan \\ Correspondence should be addressed to Nidal M. Hussein; nidal.hussein@uop.edu.jo
}

Received 18 December 2019; Revised 6 July 2020; Accepted 13 July 2020; Published 7 August 2020

Academic Editor: Richard A. Smith

Copyright (C) 2020 Nidal M. Hussein and Mohammed N. Assaf. This is an open access article distributed under the Creative Commons Attribution License, which permits unrestricted use, distribution, and reproduction in any medium, provided the original work is properly cited.

\begin{abstract}
This study focuses on the utilization of multispectral satellite images for remote water-quality evaluation of inland water body in Jordan. The geophysical parameters based on water's optical properties, due to the presence of optically active constituents, are used to determine contaminant level in water. It has a great potential to be employed for continuous and cost-effective waterquality monitoring and leads to a reliable regularly updated tool for better water sector management. Three sets of water samples were collected from three different dams in Jordan. Chl-a concentration of the water samples was measured and used with corresponding Sentinel 2 surface reflectance (SR) data to develop a predictive model. Chl-a concentrations and corresponding SR data were used to calibrate and validate different models. The predictive capability of each of the investigated models was determined in terms of determination coefficient $\left(R^{2}\right)$ and lowest root mean square error (RMSE) values. For the investigated sites, the B3/B2 (green/blue bands) model and the $\mathrm{Ln}(\mathrm{B} 3 / \mathrm{B} 2)$ model showed the best overall predictive capability of all models with the highest $R^{2}$ and the lowest RMSE values of $(0.859,0.824)$ and $\left(30.756 \mathrm{mg} / \mathrm{m}^{3}, 29.787 \mathrm{mg} / \mathrm{m}^{3}\right)$, respectively. The outcome of this study on selected sites can be expanded for future work to cover more sites in the future and ultimately cover all sites in Jordan.
\end{abstract}

\section{Introduction}

Inland waters including mainly lakes, rivers, dams, and reservoirs represent extremely valued environmental components (VECs) especially in Jordan. They play an important role in providing an appropriate habitat for species. In addition, they are considered as an essential component in hydrological, nutrient, carbon cycle, and climate regulation. They are a major source of water for drinking and irrigation purposes. They are also used in hydroenergy production and transportation and for aesthetic uses. In Jordan, a country that is facing chronic and serious challenges in securing reliable water sources for its dramatically growing population, mainly due to intense regional conflicts, particularly crisis in Syria, resulted in about $50 \%$ increase in water use for domestic purposes during the period of 2008-2017 [1]. When considering the gross domestic product (GDP) as a representation for countries' wealth and a factor for comparison, the kingdom occupies the second place in water scarcity in the Middle East after Yemen and the third in the global scale with Maldives as the most waterpoor country in the world [2]. The water per capita is less than one-tenth the international water poverty line of 1,000 cubic meters annually. As a result of this tremendous pressure on water sector in Jordan, the kingdom has made significant efforts to integrate treated wastewater into water budget. A large portion of the country's inland water bodies is mixed with treated wastewater, leaving the number of country's wastewater treatment plants to be 33 as of 2017. Effluents from many treatment plants are discharged to dams and released later to irrigate major parts of the Jordan Valley. Inland water resources (including treated wastewater) provided about $41 \%(27 \%$ surface water and $14 \%$ treated waste water) of the 1045 MCM that represents Jordan's water needs in 2017 [1]. 


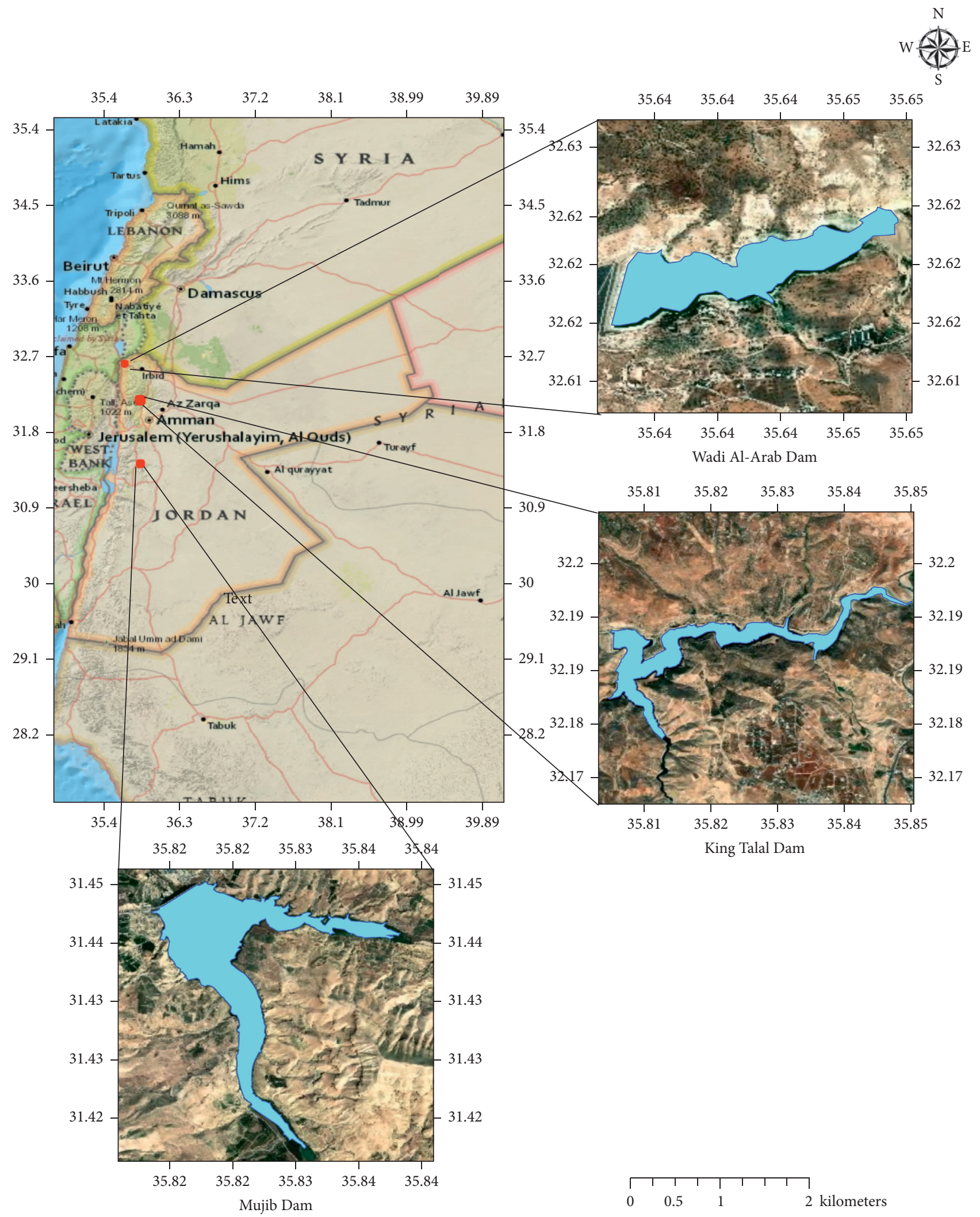

Figure 1: Jordan's map with selected dams' locations.

Climate change is expected to add extra pressure to Jordan's water sector. Climate change impacts that Jordan has experienced in recent years include precipitation decrease, temperature increase, change in precipitation patterns where rainfall season tends to be shorter with late start, base flow decrease in surface water systems, and water- 


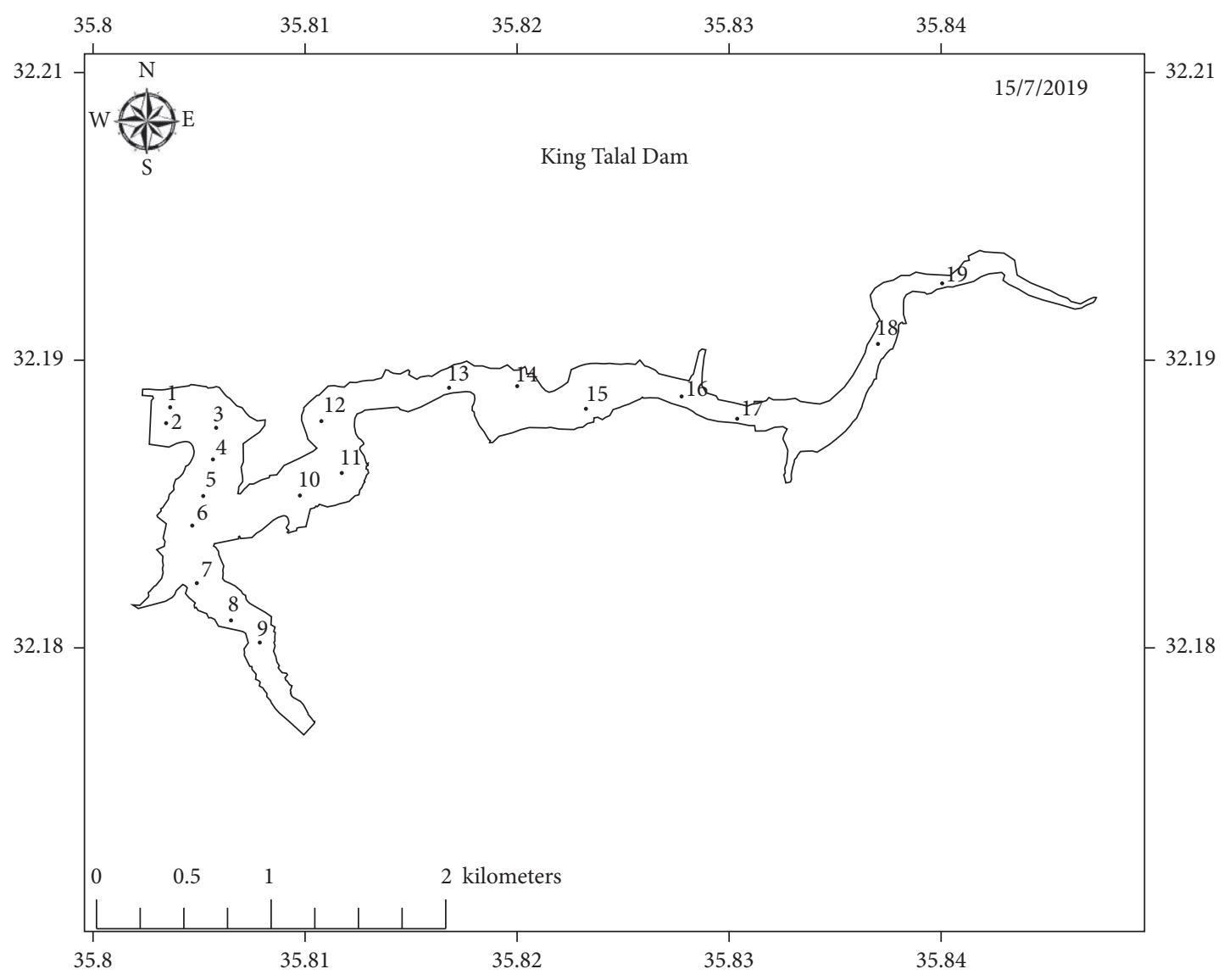

- Water sample location

FIgURe 2: Sampling points distribution of King Talal Dam.

quality deterioration [3]. Projected temperature increase will lead to increase in the high evaporation rate in the water surface.

These vulnerable water bodies are exposed to different sources of pollution. Consequently, intensive water-quality monitoring of inland water bodies and water storage facilities that provides reliable regularly updated water-quality information for a better water sector management becomes a very important obligation the country has to meet effectively. It becomes even more important due to the current water situation in Jordan and the different uses of stored surface water that covers a wide range of sectors including, but not limited to, domestic, irrigation, and industrial applications. On the other hand, the high cost associated with traditional monitoring program creates a need for an effective and cost-efficient technique.

Inland water shows high sensitivity and ability to reflect environmental changes such as climate change, land cover, and land use [4]. Continuous monitoring of such changes and patterns effectively and efficiently is of extreme importance [5-9]. Therefore, the utilization of satellite remote sensing techniques, defined as a technique that estimates geophysical parameters from the electromagnetic energy reflected or emitted from the earth [10], based on water's optical properties, due to the presence of optically active constituents, has a great potential to be employed for waterquality monitoring, especially for the case of Jordan with such a high degree of vulnerability of its water bodies.

Water remote sensing is based on the observation of the water colour from a distance, without taking water samples. It relates water colour quantitatively to the presence of certain constituents that interacts with solar radiation and change the energy spectrum of reflected radiation from water bodies. These constituents are referred to as optical water-quality parameters (WQP). Three different approaches can be used in remote sensing measurements to estimate water constituents' concentrations [11]. These approaches are the empirical method based on statistical analysis of the relation between measured spectral values and measured water parameters and the semiempirical method where the spectral features of the measured water parameters are integrated with the statistical analysis as described previously. The third type is the analytical method where the inherent optical properties (such as absorption coefficient, scattering coefficient, and volume scattering function) and apparent optical properties (such as irradiance reflectance and diffuse attenuation coefficient for downwelling irradiance) are used to model the relationships between the water-quality parameter (WQP), underwater light field, and the remotely sensed radiance. 


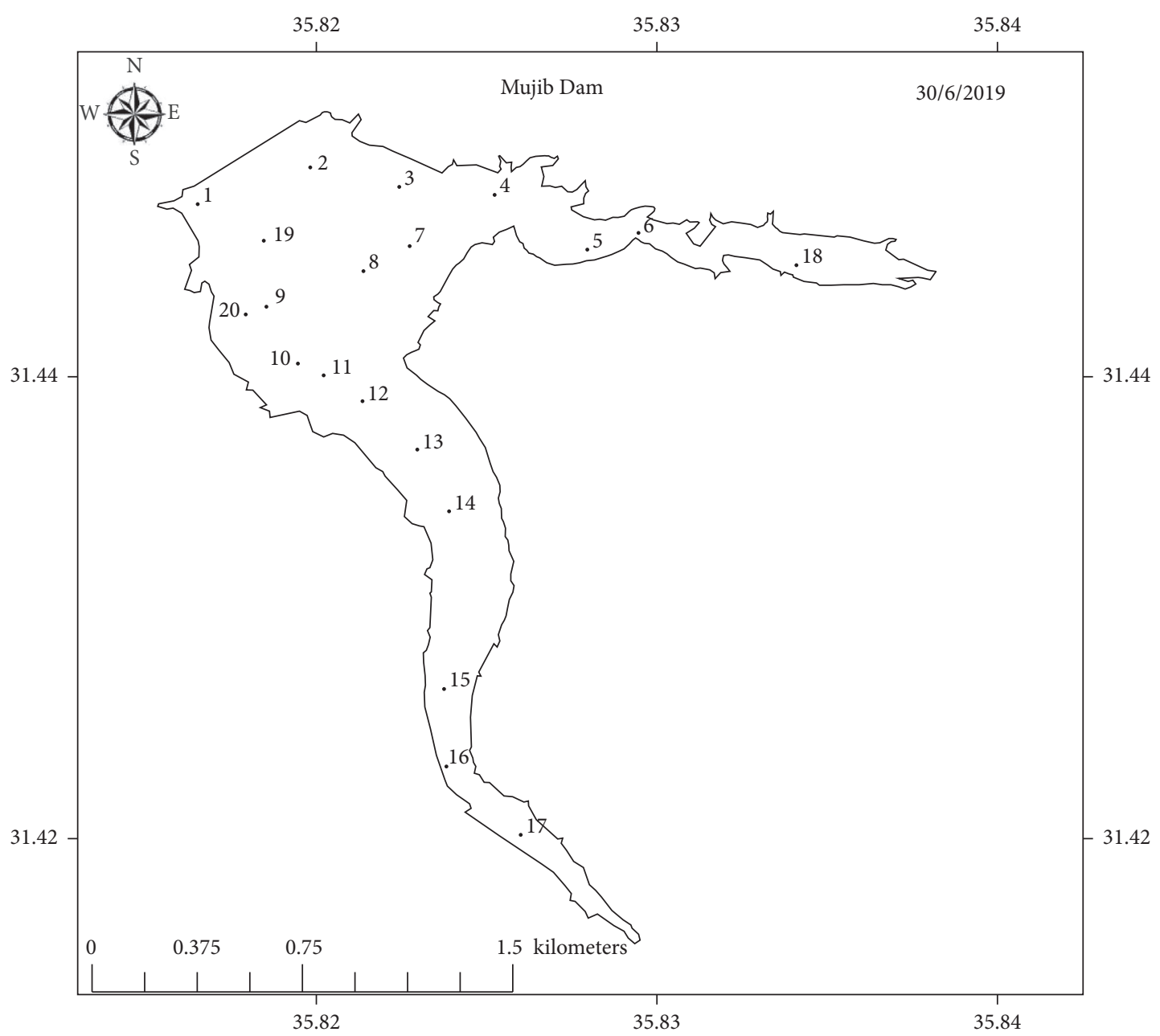

- Water samples location

FIgURE 3: Sampling points distribution of Mujib Dam.

Remote sensing techniques have been widely used to measure the qualitative parameters of water bodies. Gholizadeh et al. listed eleven water-quality parameters (WQP) that can be measured by remote sensing techniques [12]. These parameters are chlorophyll-a (chl-a), coloured dissolved organic matters (CDOM), Secchi disk depth (SDD), turbidity, total suspended sediments (TSS), water temperature (WT), total phosphorus (TP), sea surface salinity (SSS), dissolved oxygen (DO), biochemical oxygen demand (BOD), and chemical oxygen demand (COD).

In spite of its enormous possibilities, the development of water remote sensing techniques began in the early 1970 s. The early attempts of employing this technique focused on spectral and thermal measurements of reflected energy from water surfaces. Empirical relationships were developed between the spectral properties and the water-quality parameters of the water body [13]. Pionke and Blanchard and Ritchie et al. investigated the relationship of reflected solar radiation and the concentration of sediment in the surface water of reservoirs and developed an empirical approach to determine suspended sediments using this technique $[14,15]$. Dekkers et al. used airborne remote sensing for three shallow lakes with varied trophic level [16]. Wynne et al. assessed trends in lake ice breakup by monitoring ice phenology as a climate indicator where satellite-derived breakup dates were compared with available ground data [17]. Latifovic and Pouliot presented a new technique for extracting lake ice phenology events of 36 lakes from historical long-term satellite records acquired by the series of advanced sensors [8].

Jeffreis et al. and Gholizadeh et al. provided a comprehensive review on remote monitoring techniques and applications for lakes and rivers [12, 18]. Few efforts were taken in Jordan in the area of remote sensing. Recently, Avisse et al. proposed an approach that uses Landsat imagery and digital elevation models (DEMs) to obtain data on Yarmouk basin storage quantity variations in an unreachable border area between Jordan and Syria where ground monitoring is blocked by the Syrian civil war. Their data were validated against available in situ measurements in neighbouring Jordanian reservoirs [7]. Al-Bakri et al. presented a case from Jordan where geospatial techniques were utilized for irrigation water auditing, and their work was limited to assessing records of groundwater abstraction in 


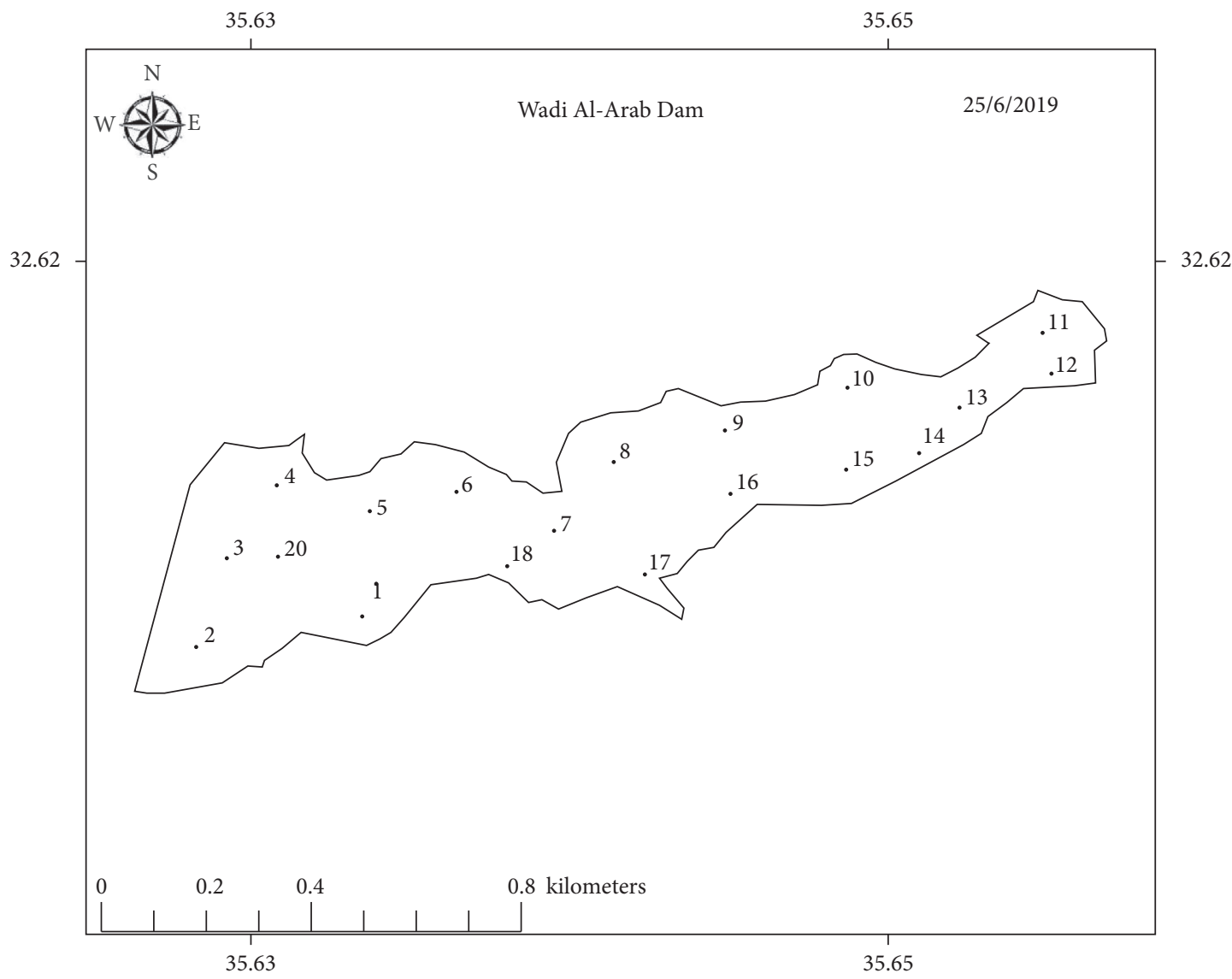

- Water samples location

Figure 4: Sampling points distribution of Wadi Al-Arab Dam.

relation to irrigated areas and estimated crop water consumption in three water basins such as Yarmouk, AmmanZarqa, and Azraq. Mapping of irrigated areas and crop water requirements was carried out using remote sensing data of Landsat 8 and daily weather records [19].

This study aims at evaluating the utilization of the emerging multispectral imaging techniques in monitoring chlorophyll-a (Chl-a) concentrations in highly sensitive and vulnerable water bodies. Chlorophyll is an optically active material present in plants and algae and special types of photosynthesis-capable bacteria (usually referred to as cyanobacteria), and it links nutrients' concentration and algal production and is considered a good indicator of waterbody's trophic state. To identify and classify the trophic state of aquatic environmental, trophic state index (TSI) has been created. It uses Chl-a as an equation parameter [20-22]. Moreover, Chl-a is considered a significant indicator of the ecological health and water quality of rivers, lakes, and reservoirs and plays a vital role in urban environmental management [23]. Chlorophyll absorbs most of violet-blue and orange-red wavelengths, reflects green, and decreases short wavelengths' response (particularly blue band wavelengths) [12]. Many researchers focused on developing correlations to estimate Chl-a concentration in water bodies with the help of remote sensing techniques, and a good number of studies were listed and reviewed by Gholizadeh and his coworkers [12]. Several researchers have used Sentinel 2 images to develop predictive models for chlorophyll-a [24-28].

Although the current study will start with selected sites, it will provide a solid basis for future work to cover more sites in the future and ultimately cover all sites in Jordan. The study will ultimately lead to the development of a mathematical model capable of predicting Chl-a concentration without the need of in situ measurement and enable remote monitoring of Chl-a concentrations of distributed water bodies across the country. Multispectral satellite images provided by international sources such as US Geological Survey (USGS) and European Space Agency will be used in this study. The outcome of this study will provide a powerful tool to water sector officials. They can use it to efficiently manage this sector with a good advantage in terms of time, effort, and cost-effectiveness by providing spatial and temporal evaluation of inlands water quality for a large geographic area compared to classical water-quality testing using direct measurement. 
TABLE 1: Chl-a concentration and corresponding sampling points' coordinates of samples collected from KTD.

\begin{tabular}{lccc}
\hline \multicolumn{3}{c}{ Visit date: $15 / 7 / 2019$} \\
Dam name: King Talal \\
Site & Latitude & Longitude & Chl-a (ppb) \\
\hline 1 & 32.191214 & 35.802659 & 113.78 \\
2 & 32.19017 & 35.802359 & 114.53 \\
3 & 32.190125 & 35.80503 & 120.58 \\
4 & 32.188527 & 35.80488 & 116.61 \\
5 & 32.186657 & 35.804386 & 103.31 \\
6 & 32.185104 & 35.803796 & 81.23 \\
7 & 32.182171 & 35.804032 & 85.55 \\
8 & 32.180246 & 35.805792 & 78.05 \\
9 & 32.179102 & 35.80724 & 76.11 \\
10 & 32.186675 & 35.809343 & 53.95 \\
11 & 32.187883 & 35.811499 & 77.92 \\
12 & 32.190443 & 35.810448 & 90.77 \\
13 & 32.192213 & 35.817026 & 104.29 \\
14 & 32.192267 & 35.820534 & 104.19 \\
15 & 32.19115 & 35.824075 & 92.51 \\
16 & 32.191776 & 35.829 & 153.86 \\
17 & 32.190541 & 35.831865 & 147.65 \\
18 & 32.19446 & 35.839118 & 155.95 \\
\hline
\end{tabular}

TABLE 2: Chl-a concentration and corresponding sampling points' coordinates of samples collected from Mujib Dam.

\begin{tabular}{lccc}
\hline \multicolumn{4}{c}{ Visit date: $30 / 6 / 2019$} \\
Dam name: Mujib \\
Site & Latitude & Longitude & Chl-a (ppb) \\
\hline 1 & 31.443241 & 35.816654 & 3.7 \\
2 & 31.444401 & 35.820263 & 2.8 \\
3 & 31.443779 & 35.823117 & 1.7 \\
4 & 31.44355 & 35.826175 & 1.4 \\
5 & 31.441765 & 35.829147 & 3 \\
6 & 31.442268 & 35.830789 & 2.8 \\
7 & 31.441938 & 35.82345 & 2.5 \\
8 & 31.441087 & 35.821969 & 2.9 \\
9 & 31.439934 & 35.818858 & 2.1 \\
10 & 31.438103 & 35.819867 & 2.34 \\
11 & 31.437737 & 35.820693 & 2.42 \\
12 & 31.436877 & 35.821938 & 2.59 \\
13 & 31.435321 & 35.823697 & 2.42 \\
14 & 31.433362 & 35.824716 & 2.9 \\
15 & 31.427677 & 35.824555 & 2.55 \\
16 & 31.425169 & 35.82463 & 2.38 \\
17 & 31.422999 & 35.827012 & 2.1 \\
18 & 31.441271 & 35.835853 & 2.4 \\
19 & 31.442076 & 35.818773 & 3.818194 \\
\hline
\end{tabular}

TABLE 3: Chl-a concentration and corresponding sampling points' coordinates of samples collected from Wadi Al-Arab Dam.

Visit date: $25 / 6 / 2019$

Dam name: Wadi Al-Arab

\begin{tabular}{lccc} 
Site & Latitude & Longitude & Chl-a $(\mathrm{ppb})$ \\
\hline 1 & 32.617107 & 35.636684 & 28.32 \\
2 & 32.616618 & 35.633839 & 50.71 \\
3 & 32.618131 & 35.634364 & 24.13 \\
4 & 32.619388 & 35.63522 & 23.46 \\
5 & 32.618911 & 35.636822 & 26.26 \\
6 & 32.619248 & 35.6383 & 31.32 \\
\hline
\end{tabular}


TABle 3: Continued.

Visit date: 25/6/2019

Dam name: Wadi Al-Arab

\begin{tabular}{lccc} 
Site & Latitude & Longitude & Chl-a (ppb) \\
\hline 7 & 32.618596 & 35.639972 & 36.43 \\
8 & 32.619783 & 35.640994 & 39.76 \\
9 & 32.620295 & 35.6429 & 36.14 \\
10 & 32.621028 & 35.645 & 34.15 \\
11 & 32.621993 & 35.648343 & 32.71 \\
12 & 32.621272 & 35.648495 & 31.12 \\
13 & 32.620707 & 35.646919 & 29.34 \\
14 & 32.619935 & 35.646227 & 31.22 \\
15 & 32.61963 & 35.644977 & 33.24 \\
16 & 32.619212 & 35.642995 & 35.58 \\
17 & 32.617827 & 35.641528 & 40.41 \\
18 & 32.617977 & 35.639169 & 39.4 \\
19 & 32.617667 & 35.636925 & 30.3 \\
20 & 32.618134 & 35.635241 & 27 \\
\hline
\end{tabular}

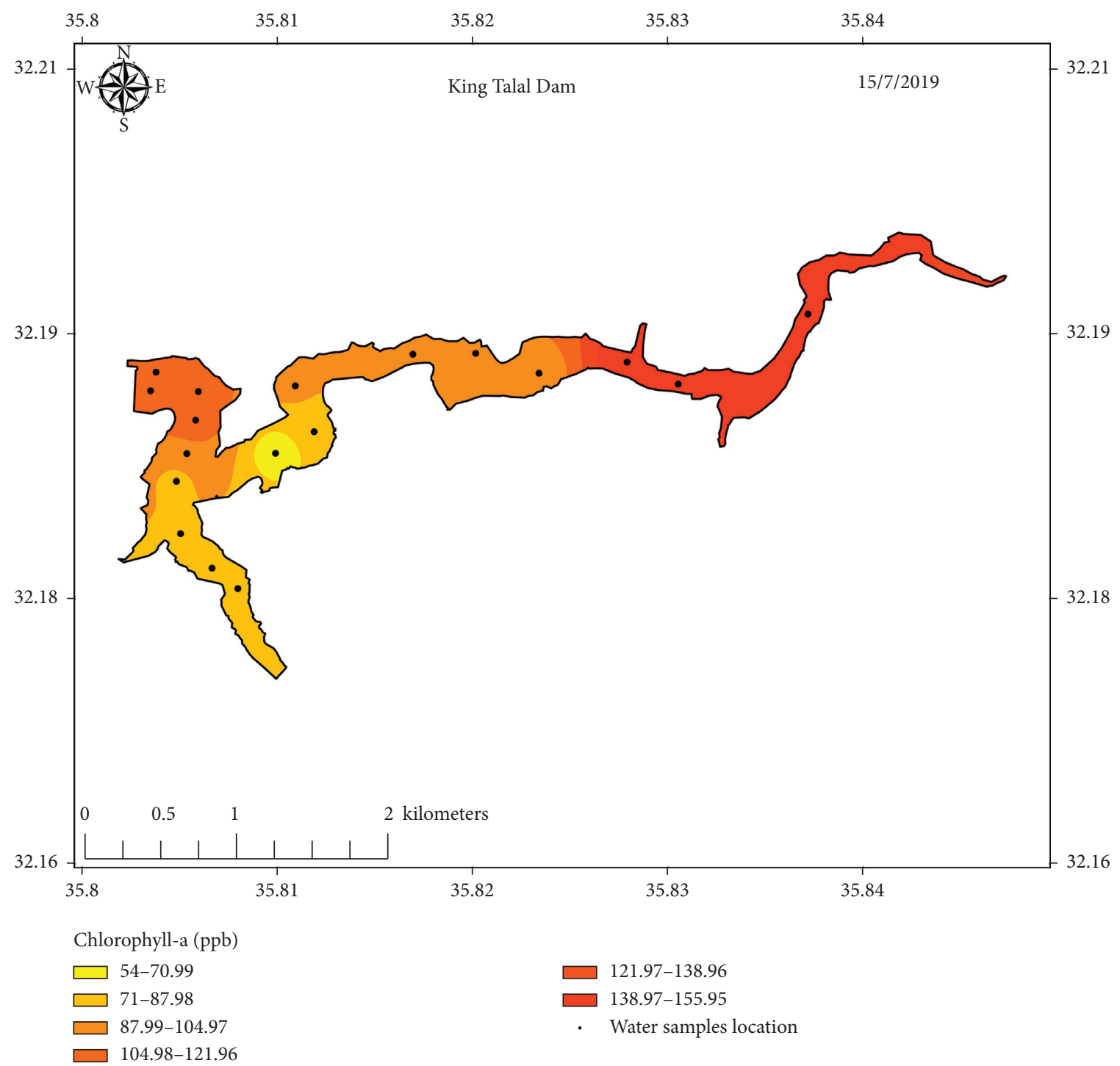

FIGURE 5: Concentration distribution of Chl-a through KTD's body. 


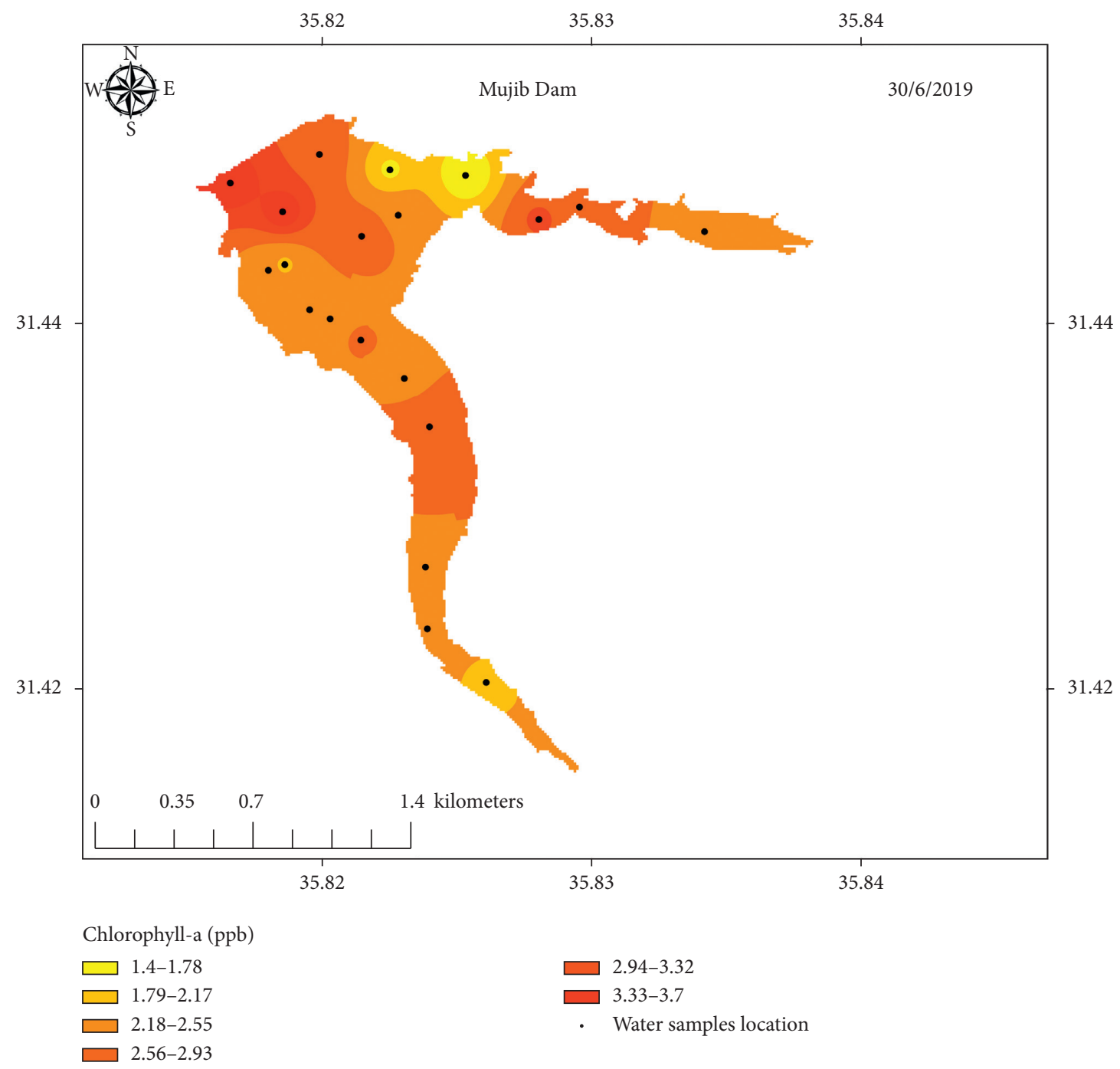

Figure 6: Concentration distribution of Chl-a through Mujib Dam's body.

\section{Methodology}

2.1. Study Area. Three dams were selected for investigation in this study: King Talal Dam (KTD), $35 \mathrm{~km}$ north of capital city Amman, Wadi Al-Arab Dam (WAD), $81 \mathrm{~km}$ north of Amman, and Mujib Dam (MD), $50 \mathrm{~km}$ south of Amman. Figure 1 shows the map of Jordan with capital city, Amman, and selected dams' locations. These dams were selected due to their importance to Jordan and their geographic distribution over the country and variation of water sources feeding them that ranges from rainfall to treated wastewater, which result in a variation in water quality in terms of Chl-a levels.

2.2. Water Sampling. Water samples were collected from the three dams, a total of 58 samples, from areas distributed through the dams' bodies. 18,20 , and 20 samples were collected from $\mathrm{KTD}, \mathrm{MD}$, and $\mathrm{WAD}$, respectively. The samples were collected about $20 \mathrm{~cm}$ below the water surface. Dark bottles were used to store collected water samples, which were transferred for analysis in a dark icebox to the water laboratory at University of Petra, Amman, Jordan. Figures 2-4 show sampling points' distribution of the three selected dams.

2.3. Sample Analysis. Collected samples were analysed for Chl-a concentration. Chlorophyll-a was tested using the EPA method number 445.0 standard methods, a common procedure followed for determination of low-level chlorophyll-a fluorescence detection of water and wastewater. Water samples were filtered at low vacuum using Whatman GF/F glass fiber filters upon arrival to the lab. Extraction of chlorophyll-a was performed using $90 \%$ acetone. A Turner Trilogy Laboratory fluorometer was used for the estimation of chlorophyll-a concentration in collected water samples. More details about the procedure followed can be found on the EPA method 445.0 technical document.

2.4. Algorithms for Chl-a Estimation. The principles of optical water properties responding to existing Chl-a in water were used to develop remote sensing algorithms for 


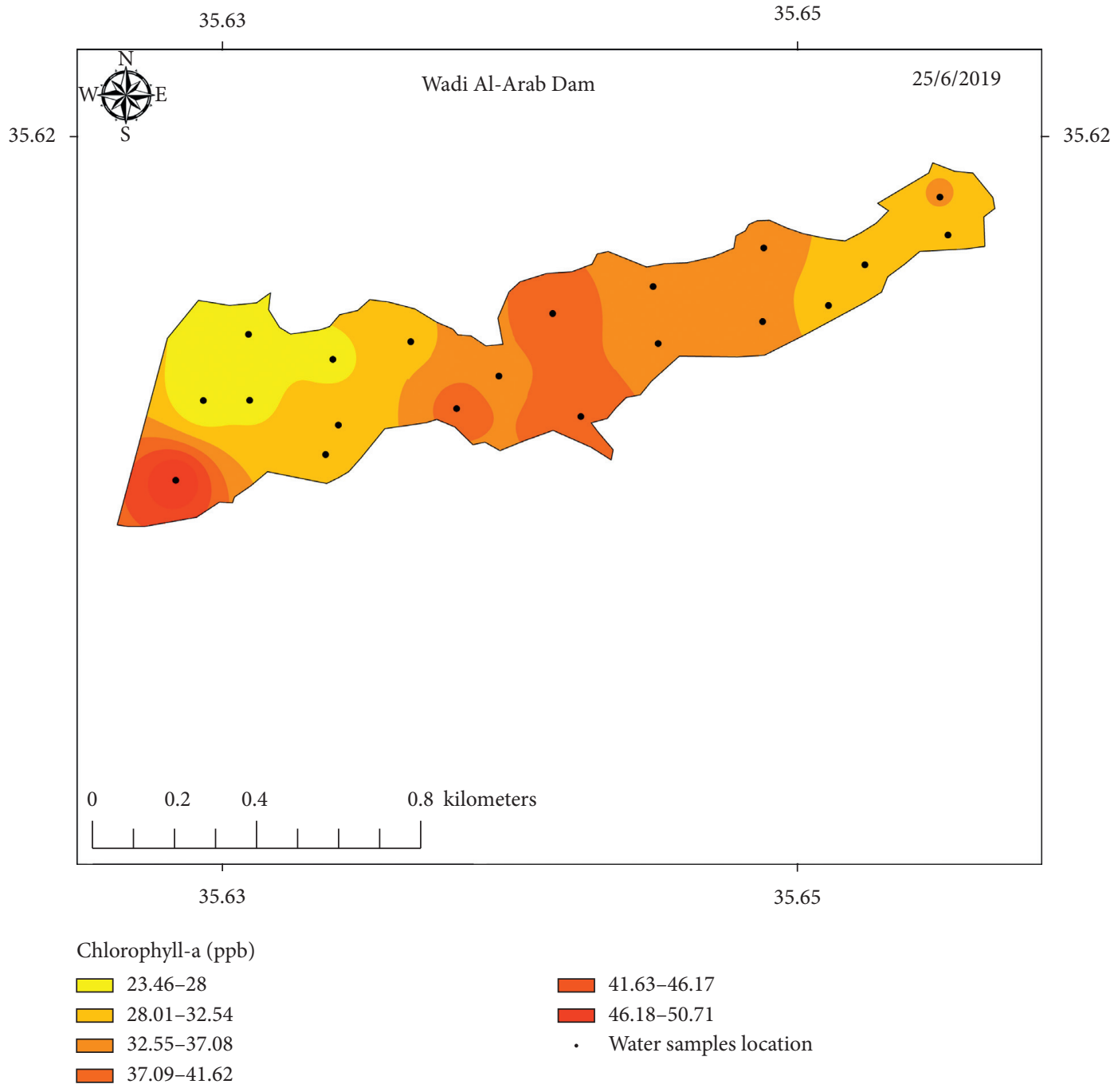

Figure 7: Concentration distribution of Chl-a through Wadi Al-Arab Dam's body.

estimating Chl-a concentration in water. The presence of Chl-a in water increases water absorption at the blue region $(443 \mathrm{~nm})$ and the near-red region $(675 \mathrm{~nm})$ [29]. The band ratio models show the ability to reduce the effect of irradiance and atmospheric and adjacent land surfaces on water reflectance. Therefore, it is more preferred to estimate Chl-a over numerous band-reflectance ratio algorithms [30]. The two commonly-used bands ratio index models are two-band ratio algorithms and three-band ratio algorithms. For the two-band ratios, the widely used band indexes are blue $(440-510 \mathrm{~nm})$ to green $(550-555 \mathrm{~nm})[31,32]$, near-infrared (NIR) $(685-710 \mathrm{~nm})$ to red $(670-675 \mathrm{~nm})[33,34]$, and green $(550-555 \mathrm{~nm})$ to red $(670-675 \mathrm{~nm})[35,36]$. Three-band ratio algorithms used one red reflectance (near-670 $\mathrm{nm}$ ) and two reflectances in the NIR region (one between 705 and 720 and another between 740 and $750 \mathrm{~nm}$ ) [37]. In this work, Sentinel 2 bands have been adopted to the two-band ratio algorithms and three-band ratio algorithms. Sentinel 2 has two bands within the blue region, one band within the green and the red region, and five bands within NIR regions, as illustrated in section four.

\section{Results}

The measured values of Chl-a concentration of samples collected from the three selected locations along with sampling points' coordinates are listed in Tables 1-3. Figures 5-7 show concentration distribution of Chl-a through the selected dams' bodies.

\section{Result Analysis and Discussion}

4.1. Sentinel 2 Image Processing. Sentinel 2 satellite imageries were selected to evaluate their suitability for investigating water quality in inland water. Sentinel 2 images were obtained from the European Space Agency through Copernicus Open Access Hub (https://scihub.copernicus.eu). Three images of level-1C (L1C) MSI data were used in this study. Table 4 summarizes Sentinel 2 images used for algorithm development.

The L1C data are obtained as digital numbers that represent top-of-atmosphere (TOA) reflectance with 10, 20, and $60 \mathrm{~m}$ bands resolution (Table 5). The images' bands were 
TABLE 4: Sentinel 2 images used for algorithm development.

\begin{tabular}{lccc}
\hline Location & Identifier & Acquisition date & Cloud cover \\
\hline KTD & S2B_MSIL1C_20190715T081609_N0208_R121_T36SYA_20190715T120216 & $2019-07-15$ \\
Mujib & S2A_MSIL1C_20190630T081611_N0207_R121_T36RYV_20190630T102130 & $2019-06-30$ \\
Wadi Al-Arab & S2B_MSIL1C_20190625T081609_N0207_R121_T36SYB_20190625T120443 & 2019-06-25 & 1.3111 \\
\hline
\end{tabular}

TABle 5: Sentinel 2 spectral bands, spatial resolution, band range, and central wavelength at reference radiance used in this study.

\begin{tabular}{lcc}
\hline Band (spatial resolution) & Band range $(\mathrm{nm})$ & Central wavelength $(\mathrm{nm})$ \\
\hline Band 1 coastal/aerosol $(60 \mathrm{~m})$ & $421-457$ & 443 \\
Band 2 blue $(10 \mathrm{~m})$ & $439-535$ & 490 \\
Band 3 green $(10 \mathrm{~m})$ & $537-582$ & 560 \\
Band 4 red $(10 \mathrm{~m})$ & $646-685$ & 665 \\
Band 5 VRE $(20 \mathrm{~m})$ & $694-714$ & 705 \\
Band 6 VRE $(20 \mathrm{~m})$ & $731-749$ & 740 \\
Band 7 VRE $(20 \mathrm{~m})$ & $768-796$ & 783 \\
Band 8 NIR $(10 \mathrm{~m})$ & $767-908$ & 842 \\
Band 8a NIR $(20 \mathrm{~m})$ & $858-881$ & 865 \\
Band 9 WV $(60 \mathrm{~m})$ & $931-958$ & 945 \\
Band 10 cirrus $(60 \mathrm{~m})$ & $1338-1414$ & 1375 \\
Band 11 SWIR $(20 \mathrm{~m})$ & $1539-1681$ & 1610 \\
Band 12 SWIR $(20 \mathrm{~m})$ & $2072-2312$ & 2190 \\
\hline
\end{tabular}

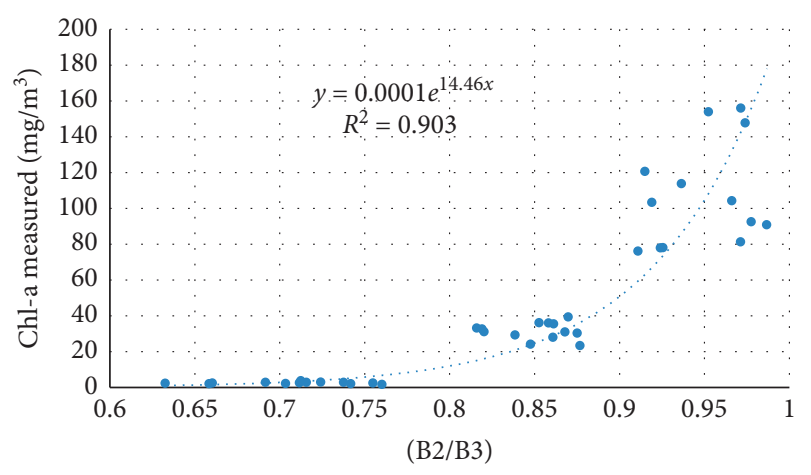

FIgURE 8: Regression between the Sentinel 2 band index and measured Chl-a, using the B2/B3 model.

resampled to $20 \mathrm{~m}$ resolution using Sentinel Application Platform (SNAP) version 6.0.

Since TOA reflectance is significantly affected by atmospheric conditions that may lead to a considerable uncertainty in the satellite data, an atmospheric correction protocol is necessary for an accurate estimation of the surface reflectance (SR) of a ground target. Atmospheric and topographic correction (ATCOR) is the most common physical methods to convert the top-of-atmosphere (TOA) to remote sensing reflectance $\left(\mathrm{R}_{\mathrm{rs}}\right)$ [38]. PCI Geomatica (2017) (ATCOR based) software was used to perform atmospheric correction to eliminate terrain and atmospheric effects.

4.2. Algorithm Development. In this study, georeferenced Chl-a concentration from the three dams (King Talal Dam, Mujib Dam, and Wadi Al-Arab Dam) and corresponding Sentinel 2 satellite pixels were used to develop a Chl-a predictive model. In total, 58 water samples were collected and considered for investigation. The collected data were divided into two sets. the first set contains 39 points and was used for calibration. The second set contains 19 points and was used for validation. The Chl-a algorithms found in the literature adopted to Sentinel 2 spectral band configuration use ratios and combinations of two bands.

Figures 8-10 present the performance of different algorithms that correlate band widths combinations with Chla measured concentration. Model calibration results using 2band models showed a very strong relationship with Chl-a than using an exponential function. The best-fitted models showed the highest $R^{2}$ of 0.907 .

4.3. Algorithm Validation. The second set of data (19 samples) was used to test the predictive capabilities of the calibrated models above. The performance of the three selected models was evaluated based on determination coefficient $\left(R^{2}\right)$, root mean square error (RMSE), mean absolute error (MAE), and bias values. Table 6 summarizes the predictive performance of different 


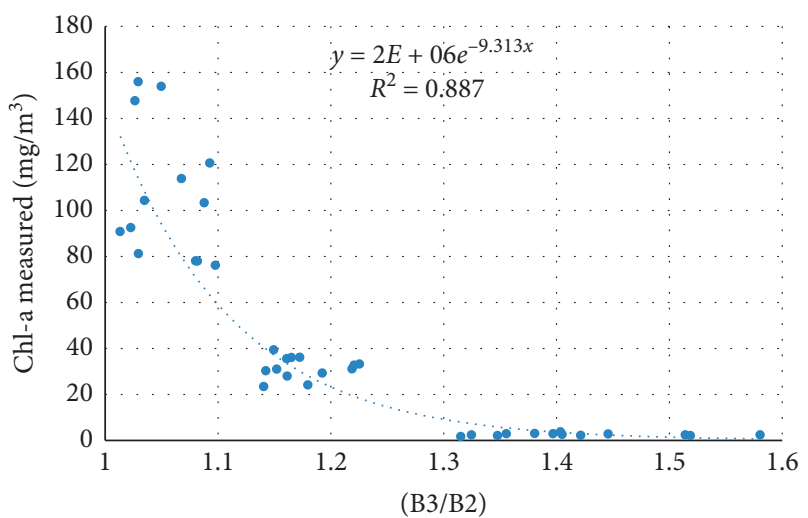

Figure 9: Regression between the Sentinel 2 band index and measured Chl-a, using the B3/B2 model.

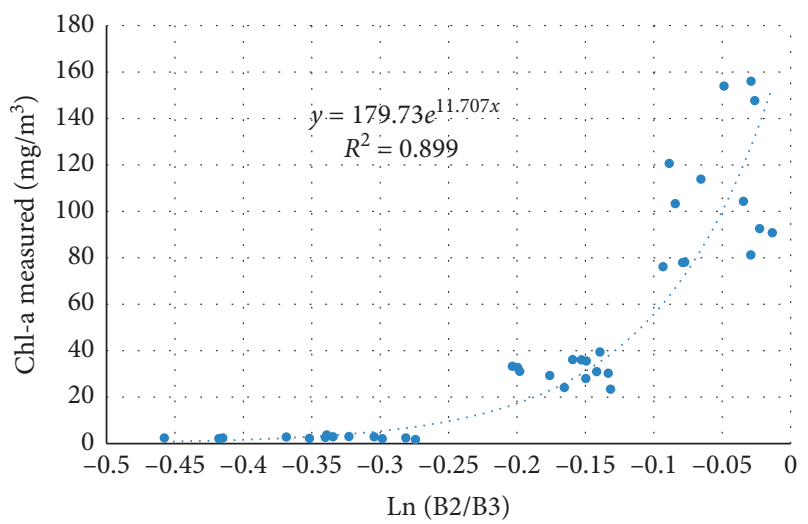

Figure 10: Regression between the Sentinel 2 band index and measured Chl-a, using the $\operatorname{Ln}(\mathrm{B} 2 / \mathrm{B} 3)$ model.

TABLE 6: Validation results of Sentinel 2 Chl-a models.

\begin{tabular}{lccccc}
\hline Index & Equation & $R^{2}$ & RMSE & MAE & Bias \\
\hline B2/B3 & $y=0.0001 \mathrm{e}^{14.46 x}$ & 0.776 & 34.668 & 18.684 & -7.561 \\
B3/B2 & $y=2 E+06 e^{-9.313 x}$ & 0.859 & 30.756 & 18.554 & -14.399 \\
$\ln ($ B2/B3 $)$ & $y=179.73 e^{11.707 x}$ & 0.824 & 29.787 & 17.338 & -9.0158 \\
\hline
\end{tabular}

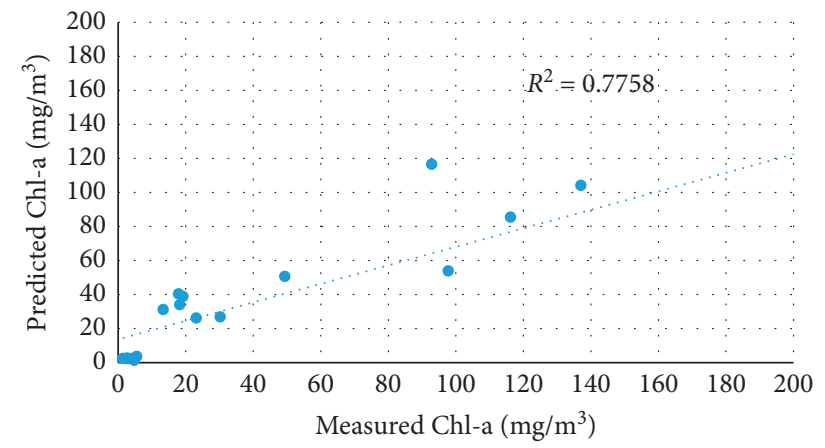

FIgURE 11: Regression between predicted and measured Chl-a using the B2/B3 model.

exponential functions applied to the blue band and green band. Figures 11-13 show a comparison between predicted and measured Chl-a using the calibrated models above.
Two-band models showed significantly better Chl-a predictive capabilities than exponential function. The B3/B2 model successfully predicted Chl-a concentrations with the highest $R^{2}$ value and a lowest root mean 


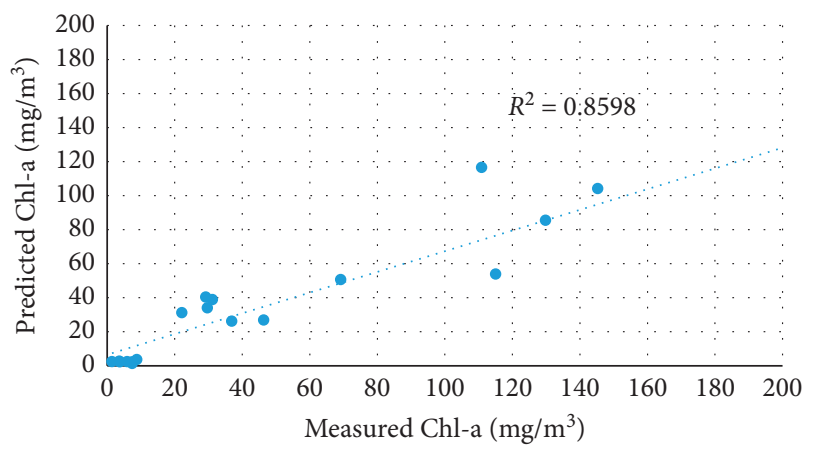

Figure 12: Regression between predicted and measured Chl-a using the B3/B2 model.

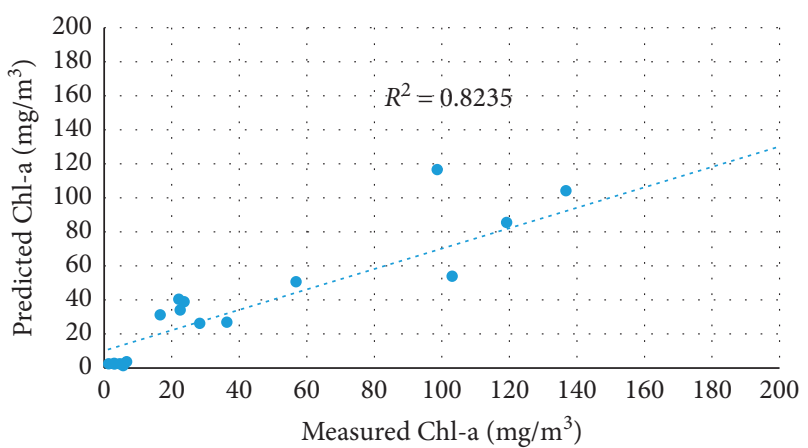

Figure 13: Regression between predicted and measured Chl-a using the $\operatorname{Ln}(\mathrm{B} 2 / \mathrm{B} 3)$ model.

square error (RMSE), respectively $\left(R^{2}=0.859\right.$, $\left.\mathrm{RMSE}=30.756 \mathrm{mg} / \mathrm{m}^{3}\right)$.

\section{Conclusions}

This study assessed the applicability and accuracy of utilizing Sentinel 2 images to evaluate and monitor Chl-a concentration in inland water bodies. Chl-a concentration of a total of 58 samples was measured. Samples were collected from three different dams in Jordan, which have different waterquality properties and large variation in Chl-a level. Chl-a concentration ranged between 1.4 and $3.7 \mathrm{mg} / \mathrm{m}^{3}, 23.4$ and $50.7 \mathrm{mg} / \mathrm{m}^{3}$, and 53.9 and $155.9 \mathrm{mg} / \mathrm{m}^{3}$ for Mujib Dam, Wadi Al-Arab Dam, and KTD Dam, respectively. The empirical model approach was applied to create a Chl-a predictive model by testing and examining several bandsbased algorithms. About two-thirds of the samples were used to develop a predictive model. The developed model was used to predict Chl-a concentration of the remaining 19 sampling points from surface reflectance (SR) data. The measured Chl-a concentrations of the validation set were compared to the corresponding predicted values obtained from developed models. The predictive capability of each of the investigated models was determined in terms of determination coefficient $\left(R^{2}\right)$ and lowest root mean square error (RMSE) values.

Several two-band ratios algorithms and a three-band ratios algorithm were tested. For the investigated sites, the linear and natural logarithm of the blue-to-green ratio model (B3/B2 model and $\operatorname{Ln}(\mathrm{B} 3 / \mathrm{B} 2)$ model) showed the best overall predictive capability of all models with the highest $R^{2}$ and lowest RMSE values of $(0.859,0.823)$ and $(30.756 \mathrm{mg} /$ $\left.\mathrm{m}^{3}, 29.787 \mathrm{mg} / \mathrm{m}^{3}\right)$, respectively. The analysis of results obtained in this study demonstrated that Sentinel 2 images can adequately be used to monitor Chl-a levels over a wide range and to assess water quality for inland water bodies.

\section{Data Availability}

All data associated with this paper are available from the corresponding author upon reasonable request.

\section{Conflicts of Interest}

The authors declare that they have no conflicts of interest.

\section{Acknowledgments}

The authors would like to thank the Deanship of Scientific Research and Graduate Studies at University of Petra (grant no. 3/7/2019).

\section{References}

[1] Ministry of Water and Irrigation, Jordan Water Sector Facts \& Figures, 2017, Ministry of Water and Irrigation, Amman, Jordan, 2017.

[2] United States Agency for International Development, Water Management Initiative Review of Water Scarcity Ranking Methodologies, United States Agency for International Development, Amman, Jordan, 2017. 
[3] Water Resources Management, Water Resources in Jordan: A Primer 2010, Water Resources Management Division Department of Environment and Conservation Government of Newfoundland and Labrador, Amman Jordan, 2010.

[4] S. R. Carpenter, B. J. Benson, R. Biggs et al., "Understanding regional change: a comparison of two lake districts," Bioscience, vol. 57, no. 4, pp. 323-335, 2007.

[5] H. Duan, R. Ma, J. Xu, Y. Zhang, and B. Zhang, "Comparison of different semi-empirical algorithms to estimate chlorophyll-a concentration in inland lake water," Environmental Monitoring and Assessment, vol. 170, no. 1-4, pp. 231-244, 2010.

[6] D. G. Hadjimitsis and C. Clayton, "Assessment of temporal variations of water quality in inland water bodies using atmospheric corrected satellite remotely sensed image data," Environmental Monitoring and Assessment, vol. 159, no. 1-4, pp. 281-292, 2009.

[7] N. Avisse, A. Tilmant, M. F. Müller, H. J. H. Zhang, and E. S. Sciences, "Monitoring small reservoirs' storage with satellite remote sensing in inaccessible areas," Hydrology Earth System Sciences, vol. 21, no. 12, 2017.

[8] R. Latifovic and D. Pouliot, "Analysis of climate change impacts on lake ice phenology in Canada using the historical satellite data record," Remote Sensing of Environment, vol. 106, no. 4, pp. 492-507, 2007.

[9] E. Chance, K. Cobourn, and V. Thomas, "Trend detection for the extent of irrigated agriculture in Idaho's snake river plain, 1984-2016," Remote Sensing, vol. 10, no. 1, p. 145, 2018.

[10] R. A. Pielke Sr, "Mesoscale modeling and satellite simulator," in International Geophysics, pp. 407-426, Elsevier, Amsterdam, Netherlands, 2013.

[11] A. Y. Morel and H. R. Gordon, "Report of the working group on water color," Boundary-Layer Meteorology, vol. 18, no. 3, pp. 343-355, 1980.

[12] M. Gholizadeh, A. Melesse, and L. Reddi, "A comprehensive review on water quality parameters estimation using remote sensing techniques," Sensors, vol. 16, no. 8, p. 1298, 2016.

[13] J. C. Ritchie, P. V. Zimba, J. H. Everitt, and R. Sensing, "Remote sensing techniques to assess water quality," Photogrammetric Engineering \& Remote Sensing, vol. 69, no. 6, pp. 695-704, 2003.

[14] H. B. Pionke and B. J. Blanchard, "The remote sensing of suspended sediment concentrations of small impoundments," Water, Air, and Soil Pollution, vol. 4, no. 1, pp. 19-32, 1975.

[15] J. C. Ritchie, J. R. McHenry, F. R. Schiebe, and R. B. Wilson, "Relationship of reflected solar radiation and the concentration of sediment in the surface water of reservoirs," Remote Sensing of Earth Resources, vol. 3, pp. 57-71, 1975.

[16] A. G. Dekker, Ž Zamurović-nenad, H. J. Hoogenboom, and S. W. M. Peters, "Remote sensing, ecological water quality modelling and in situ measurements: a case study in shallow lakes," Hydrological Sciences Journal, vol. 41, no. 4, pp. 531-547, 1996.

[17] R. H. Wynne, T. M. Lillesand, M. K. Clayton, J. J. J. P. E. Magnuson, and R. Sensing, "Satellite monitoring of lake ice breakup on the Laurentian Shield (1980-1994)," Photogrammetric Engineering Remote Sensing, vol. 64, no. 6, pp. 607-617, 1998.

[18] M. O. Jeffries, K. Morris, and N. Kozlenko, "Ice characteristics and processes, and remote sensing," in Remote Sensing in Northern Hydrology: Measuring Environmental Change, pp. 63-90, AGU Publications, Florida Avenue, WA, USA, 2013.
[19] J. Al-Bakri, S. Shawash, A. Ghanim, and R. Abdelkhaleq, "Geospatial techniques for improved water management in Jordan," Water, vol. 8, no. 4, p. 132, 2016.

[20] M. C. Lamparelli, Graus de Trofia em Corpos dl'água do Estado de São Paulo: Avaliação dos Métodos de Monitoramento, Universidade de São Paulo, São Paulo, Brazil, 2004.

[21] R. E. Carlson, “A trophic state index for lakes1," Limnology and Oceanography, vol. 22, no. 2, pp. 361-369, 1977.

[22] L. Moore and K. Thornton, Lake and Reservoir Restoration Guidance Manual, North American Lake Management Society, Merrifield, VA, USA, 1988.

[23] D. Sun, C. Hu, Z. Qiu, J. P. Cannizzaro, and B. B. Barnes, "Influence of a red band-based water classification approach on chlorophyll algorithms for optically complex estuaries," Remote Sensing of Environment, vol. 155, pp. 289-302, 2014.

[24] K. Toming, T. Kutser, A. Laas, M. Sepp, B. Paavel, and T. Nõges, "First experiences in mapping lake water quality parameters with Sentinel-2 MSI imagery," Remote Sensing, vol. 8, no. 8, p. 640, 2016.

[25] N. T. T. Ha, N. T. P. Thao, K. Koike, and M. T. Nhuan, "Selecting the best band ratio to estimate chlorophyll-a concentration in a tropical freshwater lake using Sentinel 2A images from a case study of lake Ba Be (northern vietnam)," ISPRS International Journal of Geo-Information, vol. 6, no. 9, p. 290, 2017.

[26] J. Chen, W. Zhu, Y. Q. Tian, Q. Yu, Y. Zheng, and L. Huang, "Remote estimation of colored dissolved organic matter and chlorophyll-a in Lake Huron using Sentinel-2 measurements," Journal of Applied Remote Sensing, vol. 11, no. 3, Article ID 036007, 2017.

[27] Y. Sakuno, H. Yajima, Y. Yoshioka et al., "Evaluation of unified algorithms for remote sensing of chlorophyll-a and turbidity in lake shinji and lake nakaumi of Japan and the vaal dam reservoir of South Africa under eutrophic and ultraturbid conditions," Water, vol. 10, no. 5, p. 618, 2018.

[28] M. N. Assaf, Utilizing Landsat 8 and Sentinel 2 Satellites Images for Water Quality Evaluation in King Tala Dam, German Jordanian University, Amman, Jordan, 2019.

[29] J. F. Schalles, "Optical remote sensing techniques to estimate phytoplankton chlorophyll a concentrations in coastal," in Remote Sensing of Aquatic Coastal Ecosystem Processes, pp. 27-79, Springer, Berlin, Germany, 2006.

[30] A. G. Dekker and S. W. M. Peters, "The use of the Thematic Mapper for the analysis of eutrophic lakes: a case study in The Netherlands," International Journal of Remote Sensing, vol. 14, no. 5, pp. 799-821, 1993.

[31] K. L. Carder, F. R. Chen, J. P. Cannizzaro, J. W. Campbell, and B. G. Mitchell, "Performance of the MODIS semi-analytical ocean color algorithm for chlorophyll-a," Advances in Space Research, vol. 33, no. 7, pp. 1152-1159, 2004.

[32] N. Ha, K. Koike, and M. Nhuan, "Improved accuracy of chlorophyll-a concentration estimates from MODIS imagery using a two-band ratio algorithm and geostatistics: as applied to the monitoring of eutrophication processes over Tien Yen Bay (Northern Vietnam)," Remote Sensing, vol. 6, no. 1, pp. 421-442, 2013.

[33] A. Gitelson, "The peak near $700 \mathrm{~nm}$ on radiance spectra of algae and water: relationships of its magnitude and position with chlorophyll concentration," International Journal of Remote Sensing, vol. 13, no. 17, pp. 3367-3373, 1992.

[34] A. A. Gitelson, D. Gurlin, W. J. Moses, and T. Barrow, “A biooptical algorithm for the remote estimation of the chlorophyll-a concentration in case 2 waters," Environmental Research Letters, vol. 4, no. 4, Article ID 045003, 2009. 
[35] I. Ioannou, A. Gilerson, M. Ondrusek et al., "Algorithms for the remote estimation of chlorophyll-a in the Chesapeake Bay," in Proceedings of the Ocean Sensing and Monitoring VI, Baltimore, MA, USA, May 2014.

[36] E. N. Oliveira, A. M. Fernandes, M. Kampel et al., "Assessment of remotely sensed chlorophyll-a concentration in Guanabara Bay, Brazil," Journal of Applied Remote Sensing, vol. 10, no. 2, Article ID 026003, 2016.

[37] G. Dall'Olmo, A. A. Gitelson, D. C. Rundquist, B. Leavitt, T. Barrow, and J. C. Holz, "Assessing the potential of SeaWiFS and MODIS for estimating chlorophyll concentration in turbid productive waters using red and near-infrared bands," Remote Sensing of Environment, vol. 96, no. 2, pp. 176-187, 2005.

[38] M. Bilal, M. Nazeer, J. E. Nichol et al., "A simplified and robust surface reflectance estimation method (SREM) for use over diverse land surfaces using multi-sensor data," Remote Sensing, vol. 11, no. 11, p. 1344, 2019. 